\title{
Treatment of accidental digital injection of adrenaline from an auto-injector device
}

\author{
Sean J McGovern
}

\begin{abstract}
Following an increase in the number of patients attending the accident and emergency department because of accidental injection of adrenaline from autoinjector devices prescribed for patients with severe allergic reactions, a review of published reports was undertaken to identify the best form of treatment. Local injection of phentolamine is effective for up to 13 hours after the inadvertent digital instillation of adrenaline.

( $\mathcal{A}$ Accid Emerg Med 1997;14:379-380)
\end{abstract}

Keywords: adrenaline; phentolamine; autoinjection; ischaemia

Autoinjector devices $(0.3 \mathrm{ml}$ of $1: 1000$ adrenaline (Epi-pen)), which allow patients who experience acute allergic reactions to inject themselves subcutaneously, have been available since 1980. Since then there has been a number of case reports of accidental digital instillation of adrenaline from autoinjectors, with a reported incidence estimated as one accidental injection per 50000 Epi-pen units. $^{1-8}$ Adrenaline causes intense vasoconstriction which is mediated by stimulation of postsynaptic $\alpha_{1}$ and $\alpha_{2}$ receptors in the perivascular smooth muscle, resulting in ischaemic necrosis. ${ }^{9-11}$ Empirical methods of reversing adrenaline induced digital ischaemia that have been tried unsuccessfully include immersion of the digit in warm water, application of topical glyceryl trinitrate, metacarpal nerve block, intravenous heparin/praxilene, and amyl nitrate inhalation.

In 1957 Zucker showed a reversal of the effects of an adrenaline analogue by phentolamine. ${ }^{12}$ Phentolamine is a competitive nonselective $\alpha_{1}$ and $\alpha_{2}$ adrenergic receptor blocker of relatively short duration. ${ }^{13}$ It produces vasodilatation by antagonising the vasoconstrictor effects of adrenaline. In 1969 Jordan first demonstrated the efficacy of phentolamine in a clinical situation. ${ }^{14}$ This case involved a dental assistant who had deliberately injected adrenaline into her finger to stop arterial bleeding from a laceration and developed an ischaemic digit. After the administration of 5 $\mathrm{ml}$ of $0.1 \%$ phentolamine to the finger there was reversal of the digital ischaemia. Since then there have been several case reports documenting the efficacy of phentolamine for this purpose. ${ }^{2-8}$

It has also been reported that phentolamine prevents necrosis after infiltration of dopamine and noradrenaline. ${ }^{1516}$ In these case reports, phentolamine caused an immediate change in skin colour and temperature, from cold and white to pink and warm within seven minutes.

\section{Use of phentolamine}

Phentolamine is currently available in the United Kingdom as Rogitine (Ciba), containing $10 \mathrm{mg}$ of phentolamine in $1 \mathrm{ml}$ of clear solution. Rogitine does not have a license for the reversal of adrenaline induced vasoconstriction in the United Kingdom; however, it is the only commercially available form of this drug. When using phentolamine to reverse the vasoconstrictor effects of adrenaline, care must be taken not to use too large a dose. Thus injections of phentolamine should be given locally at the site of adrenaline injection in 0.05 $\mathrm{ml}(0.5 \mathrm{mg})$ doses $(10 \mathrm{mg} / 1 \mathrm{ml}$ of solution), up to a maximum of $0.15 \mathrm{ml}$, with $20-30$ minutes elapsing between doses. The phentolamine may be diluted with $1 \%$ lignocaine. Potential side effects of phentolamine include arrhythmias and profound hypotension; however, when phentolamine has been injected locally for the reversal of adrenaline induced vasoconstriction there have been no reported side effects. ${ }^{13}$ All patients should have blood pressure and electrocardiographic monitoring for a short period after administration of phentolamine.

\section{Discussion}

A question raised by the success of phentolamine was how long after the inadvertent instillation of adrenaline would phentolamine be effective at reversing the vasoconstrictor effects. Berben et al in 1957 were able to show reversal of the ischaemic effects of adrenaline by phentolamine up to 12 hours after the adrenaline injection, ${ }^{17}$ while in 1992 Burkhart reported a case of a nurse who had her thumb saved following the local administration of phentolamine after an interval of 13 hours. ${ }^{18}$

Phentolamine should be used for the clearly defined situation of accidental digital injection of adrenaline and should not be used in the situation of high pressure injection injuries, for which the treatment remains immediate referral for surgery.

\section{CONCLUSIONS}

Local injection of phentolamine is an effective treatment for the inadvertent digital instillation of adrenaline after an interval of up to 13 hours. All accident and emergency departments should have an agreed protocol for this unusual event, as it is likely to occur more often with the increased availability of autoinjector devices. 
1 Robert JR, Kvisanda TJ. Accidental intra-arterial injection of epinephrine treated with phentolamine. Ann Emerg of epinephrine treated

2 Desmukh N, Tolland JT. Treatment of accidental epinephrine injection in a finger. J Emerg Med 1989;7:408. phrine injection in a finger. J Emerg Med 1989;7:408.

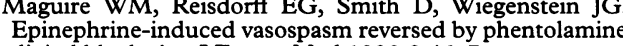
digital block. Am J Emerg Med 1990;8:46-7.

4 Markovchick V, Burkhart KK. The reversal of the ischaemic effects of epinephrine on the finger with local injections of phentolamine. J Emerg Med 1991;9:323-4.

5 McCauley WA, Gerace RV, Scilley C. Treatment of accidental digital injection of epinephrine. Ann Emerg Med 1991;20:665-8.

6 Mol CJ, Gaver J. A 39 year old nurse with accidental discharge of epinephrine autoinjector into left index finger. J Emerg Nurs 1992;18:306-7.

7 Hinterberger JW, Kintzi HE. Phentolamine reversal of epinephrine induced digital vasospasm. How to save an ischaemic finger. Arch Fam Med 1994;3:193-5.

8 Hardy SJ, Agostini DE. Accidental epinephrine autoinjector-induced digital ischaemia reversed by phentolamine digital block. J Am Osteopath Assoc 1995;95: tolamin

377-8.

Weiner N. Sympathetic amines. In: Gilman AG, Goodman LS, Rall TW, et al, eds. The pharmacologic basis of therapeutics. New York: Macmillan, 1985:145-80.
10 Gaze NR. Tissue necrosis caused by commonly used intravenous infusions. Lancet 1978;ii:417-9.

11 Weeks PM. Ischaemia of the hand secondary to levarterenol bitartrate extravasation: methods and management. JAMA 1966;196:198-200.

12 Zucker G. Use of phentolamine to prevent necrosis due to levarterenol. JAMA 1957;163:1477-9.

13 Weiner $\mathrm{N}$. Alpha-adrenergic blocking agents. In Gilman AG, Goodman LS, Rall TW, et al, eds. The pharmacologic basis of therapeutics. New York: Macmillan, 1985:181-214

14 Jordan LK. An unusual case of digital ischaemia. N C Med J 1969;30:418-9.

15 Siwy BK, Sadove AM. Acute management of dopamine infiltration injury with Rogitine. Plast Reconstr Surg 1987; 80:610-2.

16 Close AS. Phentolamine hydrochloride in prevention of cutaneous necrosis due to levarterol. JAMA 1959;170: 1916-7.

17 Berben JY, Bryant MF, Howard JM. Etiology and prevention of slough produced by L-norepinephrine. Ann Surg 1957;46:1016-20.

18 Burkhart KK. The reversal of the ischaemic effects of epinephrine on a finger with local injections of phentolamine [letter and comment]. J Emerg Med 1992;10:496.

\section{International Conference: Management of Fire and Explosions}

\section{8-9 December 1997}

Institution of Mechanical Engineers, London

The conference will cover the following areas:

- Regulations and losses (chairman Professor Phil Bennett, Hazards Forum)

- Safety culture (chairman Martin Barnard, Symonds Travers Morgan)

- Analysis (chairman Graham Dalzell, BP Exploration)

- Hazards and their management (chairman Professor Sir Bernard

Crossland, Queen's University, Belfast)

Further details from: Anne Lomax, Conference and Events, Institution of Mechanical Engineers, 1 Birdcage Walk, London SW1H 9JJ. Phone +44 (0)171 973 1261; fax +44 (0)171 222 9881; email a_lomax@imeche.org.uk 